\title{
The Short Child with Subnormal Plasma Somatomedin $\mathbf{C}^{\mathbf{1}}$
}

\author{
DANIEL RUDMAN, MICHAEL H. KUTNER, AND RAJENDER K. CHAWLA
}

Departments of Medicine and Biometry, Emory University School of Medicine, Atlanta, Georgia 30322 and Department of Medicine, University of Health Sciences/The Chicago Medical School, North Chicago, Illinois 60064

\begin{abstract}
In 59 male and 59 female healthy children of average stature between 7 and $10 \mathrm{yr}$ old, the normal range of plasma somatomedin $C$ was investigated. The 95\% tolerance limits narrowed progressively when the child's plasma somatomedin $\mathrm{C}$ status was described by the mean of one, two, three, or four determinations at 6-wk intervals. The $95 \%$ tolerance limits were therefore based on the mean of four determinations. In 97 children, age 7 to 10 , below the 3.0 percentile in height, 44 had an average plasma somatomedin $C$ below the 2.5 percentile. Among these hyposomatomedinemic short children, 19 were partially or totally deficient in growth hormone, 20 had normal immunoreactive growth hormone responses to dopa, glucagon, and sleep (nongrowth hormone deficient), and five had borderline provocative tests. Both growth hormone deficient and nongrowth hormone deficient children showed significant linear growth responses to 6-month courses of human growth hormone $(0.16$ to $0.70 \mathrm{unit} / \mathrm{kg} / \mathrm{wk})$. The responses of the latter group were 50 to $90 \%$ as great as those of the former. (Pediatr Res 19: 975-980, 1985)
\end{abstract}

\section{Abbreviations}

SmC, somatomedin C

GH, growth hormone

GHD, growth hormone deficient

Non-GHD, nongrowth hormone deficient

RIA, radioimmunoassay

hGH, human growth hormone

ACTH, adrenocorticotropic hormone

TSH, thyroid-stimulating hormone

Until recently, identification of GHD children required measurement of the serum level of immunoreactive $\mathrm{GH}$ during provocative tests, after exercising or during sleep. In 1977, an alternative approach became possible with the introduction of the RIA for SmC (1). It soon became apparent that there were substantially more short children with low SmC levels than there were GHD children (2). Some of the hyposomatomedinemic boys and girls who had normal levels of immunoreactive $\mathrm{GH}$ responded with accelerated linear growth to treatment with hGH (3-5). It was suggested that these responsive, non-GHD short children might have a structurally abnormal form of endogenous GH (3-6).

The present study had these objectives. (a) To estimate toler-

Received May 22, 1984; accepted May 1, 1985

Supported in part by NIH Grants AM-31149 and RR-00039 and by a grant from the Veterans Administration.

${ }^{1}$ Presented in part at a workshop on Human Growth Hormone, National Pituitary Agency, Baltimore, MD, October, 1984. ance limits for plasma $\mathrm{SmC}$ in children of normal height, 7 to $10 \mathrm{yr}$ old. (b) To estimate the prevalance of subnormal SmC in the population of short (less than third percentile) children, age 7 to 10 . (c) To estimate the prevalence of GHD in those children with low SmC. (d) To compare the linear growth responses to hGH treatment between hyposomatomedinemic, GHD short children and hyposomatomedinemic, non-GHD short children.

\section{METHODS}

The study proceeded in two phases. Phase 1: determination of the prediction limits of plasma $\mathrm{SmC}$ in healthy children, 7 to 10 yr old, of normal stature (5th to 95th percentile for chronologic age). Phase 2: measurement of plasma SmC in 97 children age 7 to 10 , who were below the third percentile in height for chronological age. We selected those children whose SmC level was below the normal mean for chronologic age by at least 2 SD. These children were evaluated to classify them as GHD or nonGHD. Both groups of children then received hGH for 6 months at standard doses, to determine the linear growth responses to the hormone.

Methods: Phase 1. For each yearly interval between 7 and 10 $\mathrm{yr}, 14$ or 15 healthy prepubertal children were referred by local pediatricians. They met these criteria: (a) height between the 5th and 95th percentile; (b) body weight between 95 and $115 \%$ of ideal; (c) no known chronic medical condition; (d) no drug treatment during the period of study; (e) normal history and physical examination within 6 months before the beginning of the study; (f) normal hemogram and urinalysis within 6 months before the beginning of the study.

In addition, seven prepubertal GHD children whose clinical data are given in Table 1, were studied. Criteria for diagnosing deficiency of $\mathrm{GH}$ and other pituitary hormones have been given before (4). These criteria included a mean peak immunoreactive $\mathrm{GH}$ level less than $4 \mathrm{ng} / \mathrm{ml}$ during four pharmacologic provocative tests (L-dopa or glucagon), as well as a plasma level of SmC less than $0.30 \mathrm{unit} / \mathrm{ml}$. Deficiencies of $\mathrm{ACTH}$, TSH, or antidiuretic hormone, when present, were treated as described elsewhere (4). Human GH had not been given for at least 3 months.

Blood for SmC was drawn in EDTA at 1300 to 1600 . The blood was spun immediately at $25^{\circ} \mathrm{C}$ for $10 \mathrm{~min}$; the plasma was then stored at $-20^{\circ} \mathrm{C}$ and mailed in dry ice within 2 wk to Nichols Institute, Los Angeles, for analysis by RIA (1). Intraand interassay coefficients of variation were 6 and $10 \%$, respectively.

Methods: Phase 2. The subjects in phase 2 were 97 prepubertal children, 7 to 10 yr old, referred to this clinic during 1978 to 1983 because of height less than third percentile for chronologic age (Table 2). They were referred by the same group of pediatricians as the controls in phase 1 , and had not previously been evaluated for cause of short stature. Exclusion criteria were: birth weight $<5.5 \mathrm{lb}$; previously diagnosed gastrointestinal, pulmo- 
Table 1. Clinical data of the GHD subjects (phase 1)

\begin{tabular}{clcccccc}
\hline Case & Cause of GHD & Age $(\mathrm{yr})$ & Sex & Ht $(\mathrm{cm})$ & Wt $(\mathrm{kg})$ & Bone age (yr) & Hormone deficiency \\
\hline 1 & Idiopathic & 7 & $\mathrm{~F}$ & 103 & 20 & 4 & GH \\
2 & Craniopharyngioma & 10 & $\mathrm{M}$ & 125 & 27 & 7 & GH, ACTH, TSH, ADH \\
3 & Idiopathic & 8 & $\mathrm{~F}$ & 109 & 18 & 5 & GH, ACTH \\
4 & Idiopathic & 7 & $\mathrm{~F}$ & 100 & 21 & 4 & GH \\
5 & Idiopathic & 7 & $\mathrm{M}$ & 106 & 22 & 4 & GH, TSH \\
6 & Idiopathic & 8 & $\mathrm{~F}$ & 112 & 24 & 5 & GH, TSH \\
7 & Craniopharyngioma & 8 & $\mathrm{M}$ & 115 & 19 & 6 & GH, ACTH, TSH, ADH \\
\hline
\end{tabular}

Table 2. Clinical data base summary of short children studied in phase 2 (values are mean $\pm S E$ )

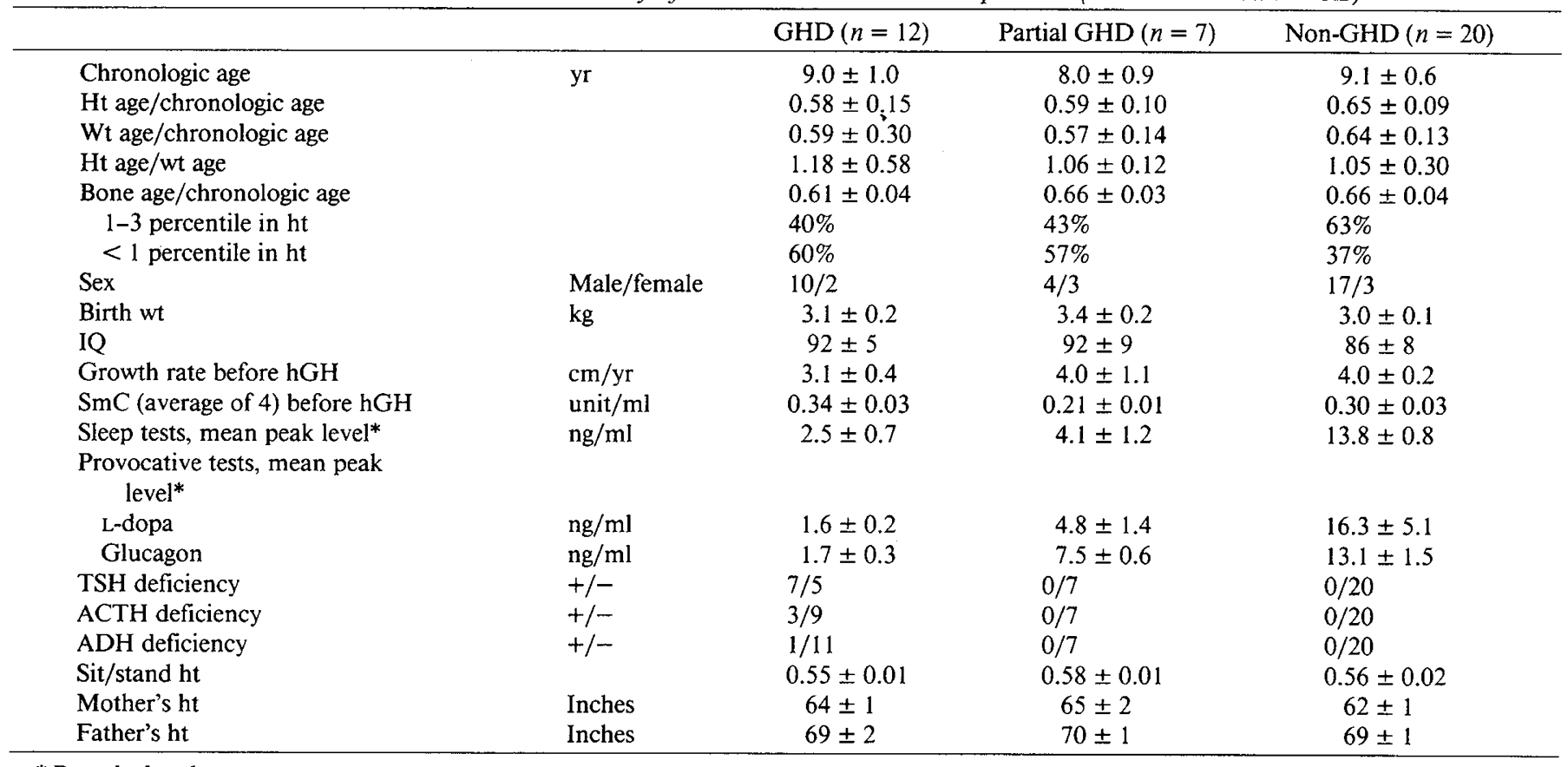

* By polyclonal assay.

nary, renal, hepatic, endocrine, or metabolic disease; chronic treatment with steroids or ritalin; previously diagnosed Turner syndrome; clinical evidence of psychosocial deprivation; history of birth trauma. Mental retardation, seizures, and congenital heart disease not causing heart failure or cyanosis were not exclusions.

At entry we began to measure the child every 2 wk on a wallmounted stadiometer. This continued as long as the child remained in the study. All children had four plasma SmC determinations at 6 -wk intervals. Those with average $\mathrm{SmC}$ below the lower 2.5 percentile tolerance limit for chronologic age ("hyposomatomedinemic children") as defined during phase 1 , then received the clinical evaluation for growth retardation described previously (4). Two or more provocative tests were done with dopa or glucagon (7) (if the peak value in the first two provocative tests averaged $>12 \mathrm{ng} / \mathrm{ml}^{2}{ }^{2}$ no more tests were done; if the first two peaks averaged $<12 \mathrm{ng} / \mathrm{ml}$, two further tests were done).

The hyposomatomedinemic children then entered 6-month alternating periods of treatment with $\mathrm{hGH}$. During each period, one of four logarithmically equally spaced doses was administered: $0.16,0.26,0.43$, and $0.70 \mathrm{unit} / \mathrm{kg} / \mathrm{wk}$, given in equally divided doses Monday, Wednesday, and Friday at 2200. The order of doses was randomized. The number of children who completed three, two, or only one period of hGH treatment were 25,18 , and 3 , respectively.

\footnotetext{
${ }^{2}$ The conventional, commercially available RIA with polyclonal rabbit antiserum was used to measure immunoreactive $\mathrm{GH}$ in the provocative tests. Our technique for carrying out this assay is described under "Methods" in the accompanying report (8).
}

\section{RESULTS}

Phase 1.

Variability studies. In three normal prepubertal 10-yr-old girls, we estimated four sources of variability associated with the measurement of plasma SmC samples. A single plasma sample for each girl was split into three aliquots and sent to Nichols Institute in a single blind fashion. Plasma samples also were collected on 3 consecutive days and at 6-wk intervals over 4 consecutive months. This allowed us to estimate intra-assay, dayto-day, and month-to-month variability.

The data, which are filed with the National Auxiliary Publication Service as document 04318, showed the following: intraassay variability $=0.0015$, estimated coefficient of variation $=$ $4.3 \%$; day to day variability $=0.0115$, estimated coefficient of variation $=11.9 \%$; month to month variability $=0.0627$, estimated coefficient of variation $=30.1 \%$. The substantial amount of month to month variability in plasma SmC samples suggested that single determinations would be of limited value in estimating tolerance limits for normal children.

Estimating tolerance intervals (normal values). The lower limit of the $95 \%$ tolerance limits based on single plasma SmC samples always was below the sensitivity of the assay $(<0.10 \mathrm{unit} / \mathrm{ml})$ (Table 3). Therefore we investigated the feasibility of estimating tolerance limits for normal children based on the average of several monthly plasma SmC samples.

Separate tolerance limits were estimated for each sex and age group based on the average of one, two, three, or four determinations of plasma $\mathrm{SmC}$ samples obtained at 6-wk intervals. The tolerance limits for each sex and age group are summarized in 


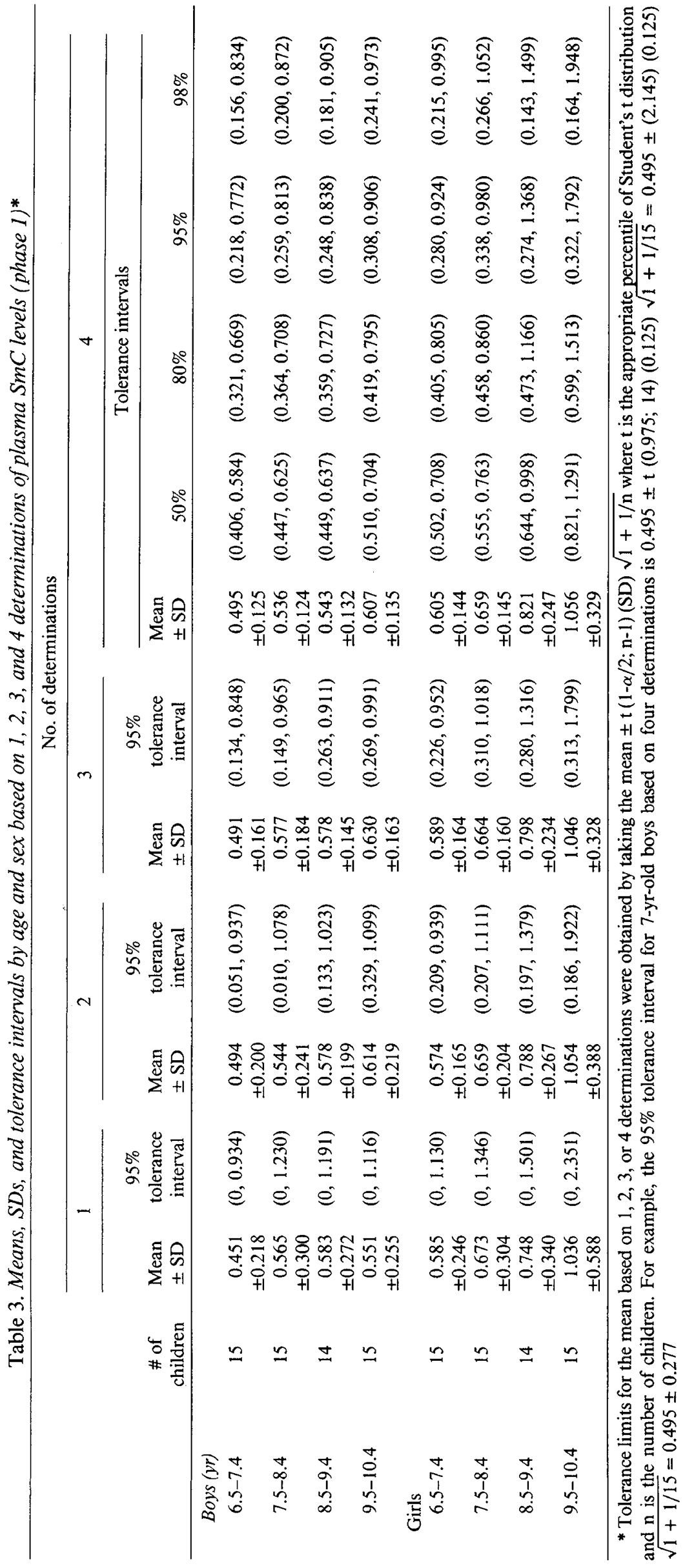


Table 3 and Figure 1. Note the decrease in the width of the tolerance intervals as the number of determinations increased.

Figure 2 displays tolerance limits for girls and boys, age 7 to 10 , for commonly used percentiles based on the average of four determinations at 6 -wk intervals. These tolerance limits can be used to screen short children for GHD. If we define subnormal as the lower limit of the $95 \%$ tolerance intervals, then two or more SmCs per child are required before the lower limit of the $95 \%$ tolerance interval rises into a measurable range ( $>0.10$ unit/ $\mathrm{ml}$ ) (Fig. 1). Since the lower limit rises progressively using the average of two, three, and four determinations (Fig. 1), it is likely that more children with partial or total GHD would be identified according to the order $(4)>(3)>(2)>(1)$. To test this hypothesis, we measured $\mathrm{SmC}$ at 6-wk intervals in seven GHD children (Table 4). If we define subnormal $\mathrm{SmC}$ as below the lower limit of the $95 \%$ tolerance intervals, then based on the mean of one, two, three, or four determinations we would classify, a posteriori, zero, three, three, and seven of the GHD children as hyposomatomedinemic, respectively. Thus, no less than four determinations were necessary in order to identify all seven GHD children as having abnormally low SmC levels.

Phase 2.

Distribution of SmC in 97 short children 7-10 yr old. In each child, plasma SmC was measured four times at 6-wk intervals, and the SmC status was represented as the average of the four values. Figure 3 compares the distribution of the mean of four $\mathrm{SmC}$ values in the 97 short children with those of the normal children determined in phase 1 . A significant excess of low $\mathrm{SmC}$ values was found. When $\mathrm{SmC}$ was less than the lower 2.5 percentile established for normal children, the child was considered "hyposomatomedinemic." Forty-five percent of the short children (44 of 97) were in this category.

Classification of the 44 hyposomatomedinemic short children. These children were evaluated for growth retardation as described in Reference 4 . When the mean peak immunoreactive $\mathrm{GH}$ level was less than $4 \mathrm{ng} / \mathrm{ml}$ in four provocative tests, the child was classified GHD. If the mean value was $4-8 \mathrm{ng} / \mathrm{ml}$, the child was classified as partial GHD. A mean value over $12 \mathrm{ng} / \mathrm{ml}$ was interpreted as a normal immunoreactive GH level and the child as non-GHD; mean values between 8 and 12 were classified as indeterminate. ${ }^{3}$ The numbers of children in the four groups were $12,7,20$, and 5 , respectively. Children in the indeterminate group will not be considered further in the present report.

Clinical characteristics for the GHD, partial GHD, and non$G H D$ groups. These characteristics are given in Table 2. Males predominated in all three groups. Anthropometric and auxologic features were similar. TSH or ACTH deficiency was common in GHD, but was not found in partial GHD or non-GHD subjects.

Responses to $h G H$ by $G H D$ and non-GHD children. There were sixty-five 6-month trials at one of the four standard doses as summarized in Table 5 (GHD and partial GHD are considered as one group). GHD children responded to all four doses of hormone; the responses to 0.43 and $0.70 \mathrm{unit} / \mathrm{kg} / \mathrm{wk}$ were similar. In the non-GHD children, one trial at $0.16 \mathrm{unit} / \mathrm{kg} / \mathrm{wk}$ was ineffective; average responses (increases in growth velocity) to $0.26,0.43$, and $0.70 \mathrm{unit} / \mathrm{kg} / \mathrm{wk}$ were $50-90 \%$ as great as in the GHD group. At the two intermediate doses, the responses of non-GHD children were significantly less than by GHD children.

\section{DISCUSSION}

Defining the normal range for plasma $S m C$. A study similar to the present one, but based on only one $\mathrm{SmC}$ determination per child, was published by Bala et al. (9). We have estimated from their graphic data the mean $\mathrm{SmC} \pm 1$ SD for ages 7-9 to be $0.46 \pm 0.30 \mathrm{unit} / \mathrm{ml}$ for boys, and $0.66 \pm 0.31$ for girls. Our results are in close agreement with those of Bala et al. For

\footnotetext{
${ }^{3}$ As stated in "Methods," if the mean peak value of the first two provocative tests was $>12 \mathrm{ng} / \mathrm{ml}$, no further tests were done; otherwise, four tests were done
} and the mean of the peak values was calculated.

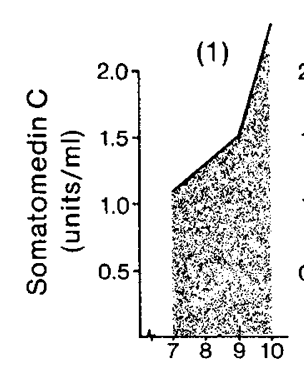

(A) Girls

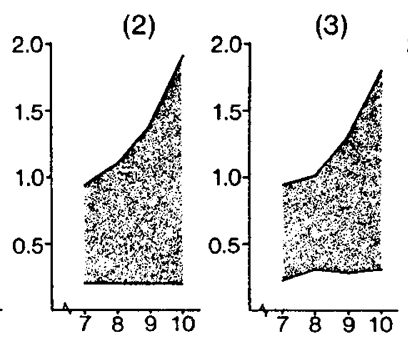

(4)

(B) Boys
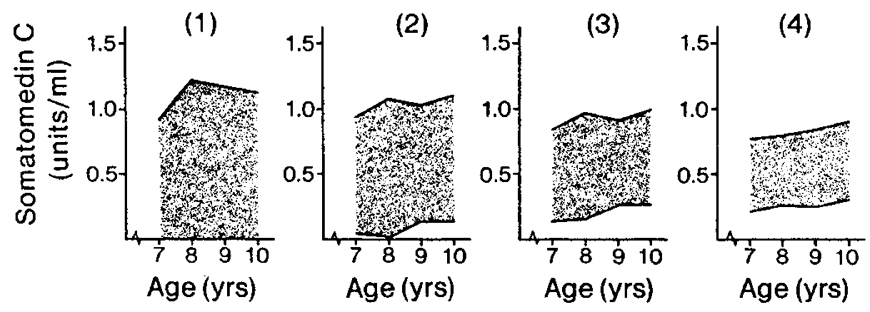

Fig. 1. $95 \%$ tolerance intervals of plasma SmC by age for girls and boys based on one, two, three, and four determinations.
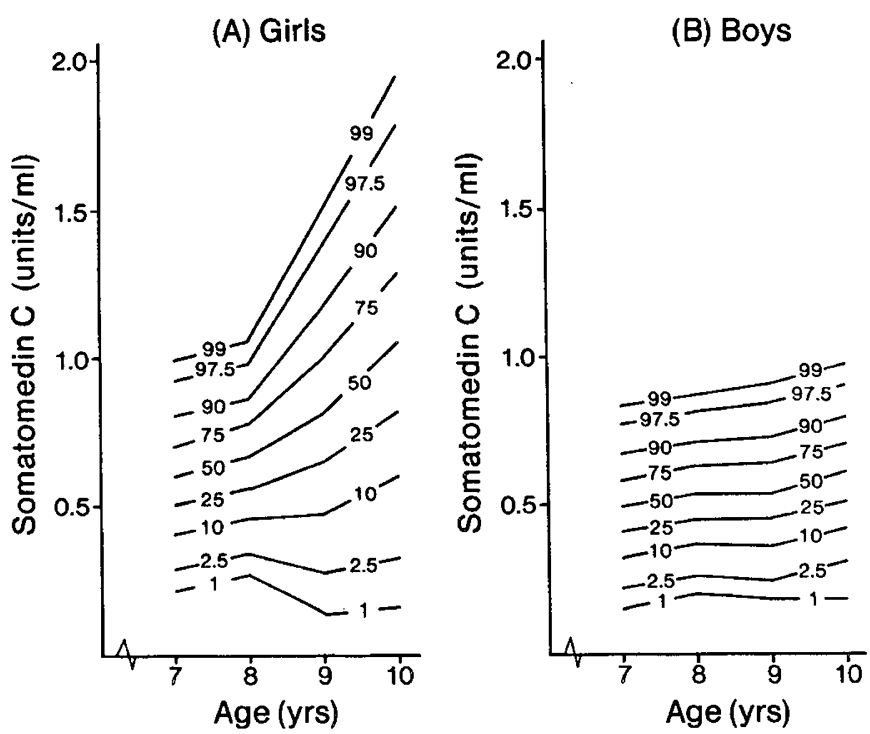

Fig. 2. Percentiles for plasma $\mathrm{SmC}$ based on the average of four determinations in normal children by sex and age.

Table 4. SmC values at 6-wk intervals of $7 \mathrm{GHD}$ children (phase 1)

\begin{tabular}{ccccc}
\hline Subject no. & \multicolumn{5}{c}{ Individual SmC values } \\
\hline 1 & 0.14 & 0.26 & 0.29 & 0.19 \\
2 & 0.13 & 0.14 & 0.26 & 0.15 \\
3 & 0.25 & 0.19 & 0.28 & 0.16 \\
4 & 0.25 & 0.24 & 0.21 & 0.19 \\
5 & 0.20 & 0.22 & $<0.10$ & 0.22 \\
6 & 0.11 & 0.25 & 0.36 & 0.20 \\
7 & 0.33 & 0.14 & $<0.10$ & 0.24 \\
\hline
\end{tabular}

example, in the present study, single determinations at age 7.58.4 resulted in a mean value of $0.57 \pm 0.30 \mathrm{unit} / \mathrm{ml}$ for boys, and $0.67 \pm 0.30$ for girls.

Tolerance limits based on the average of four determinations at 6-wk intervals were clearly preferable to fewer than four determinations. For example, the widths of the $95 \%$ tolerance intervals for the 7 -yr old boys were $0.934,0.886,0.714$, and $0.554 \mathrm{unit} / \mathrm{ml}$ based on one, two, three, and four determinations, 


\section{Short Children}
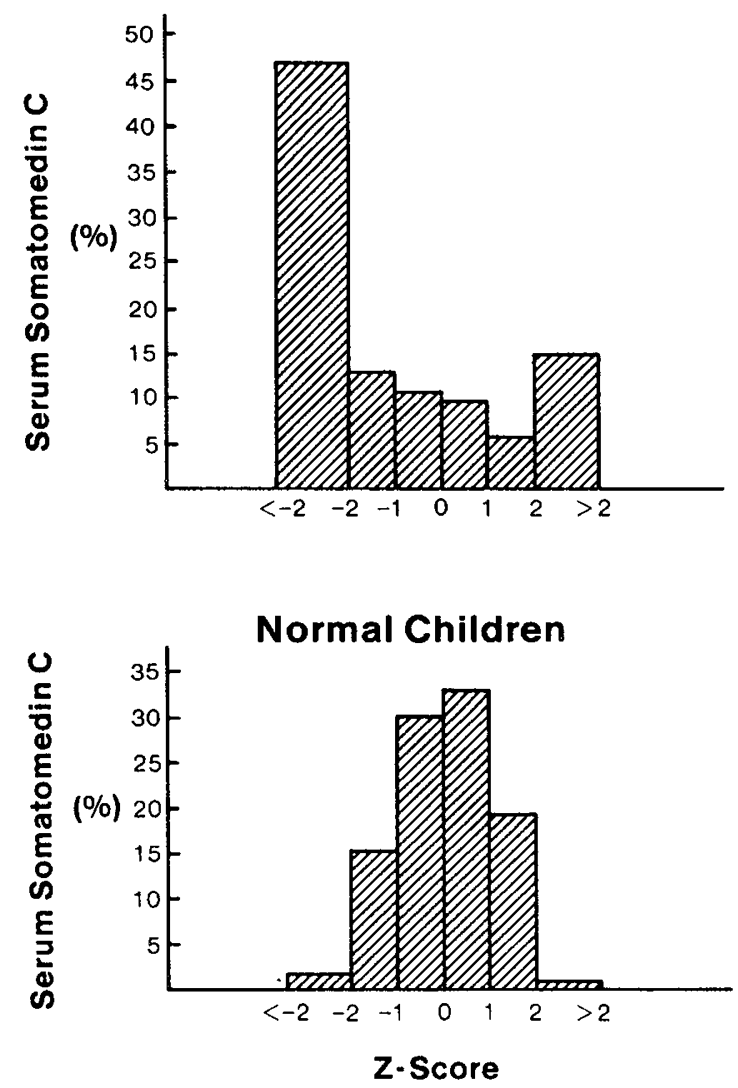

Fig. 3. Distribution of plasma SmC values (average of four) among (i) 87 normal prepubertal children, age $7-10$, between 5 and $95 \%$ in height for chronological age, and (ii) 97 prepubertal children of the same age, less than third percentile in height for chronologic age.

Table 5. Linear growth responses of GHD and non-GHD hyposomatomedinemic short children to 6-month courses of 4 different doses of $h G H$ (phase 2) (values are mean $\pm S E$ )

\begin{tabular}{|c|c|c|}
\hline \multirow{2}{*}{$\begin{array}{c}\text { Dose hGH } \\
\text { (units/kg/wk) }\end{array}$} & \multicolumn{2}{|c|}{$\begin{array}{l}\text { Increase in growth velocity } \\
\qquad(\mathrm{cm} / \mathrm{yr})\end{array}$} \\
\hline & GHD & Non-GHD \\
\hline 0.16 & $\begin{array}{c}4.35 \pm 0.66 \\
(n=8)\end{array}$ & $\begin{array}{c}0.2 \\
(n=1)\end{array}$ \\
\hline 0.26 & $\begin{array}{c}7.43 \pm 1.15 \\
(n=9)\end{array}$ & $\begin{array}{c}3.44 \pm 0.69^{*} \\
(n=16)\end{array}$ \\
\hline 0.43 & $\begin{array}{c}8.68 \pm 0.89 \\
(n=12)\end{array}$ & $\begin{array}{c}5.43 \pm 0.66^{*} \\
(n=12)\end{array}$ \\
\hline 0.70 & $\begin{array}{c}8.25 \pm 1.09 \\
(n=4)\end{array}$ & $\begin{array}{c}7.27 \pm 1.96 \\
(n=3)\end{array}$ \\
\hline
\end{tabular}

* Statistically different from GHD group, $p<0.02$.

respectively. The width of the $95 \%$ tolerance interval based on five determinations at 6-wk intervals was estimated to be 0.495 , by modifying the estimate of the SD to be based on five instead of four determinations. Because the estimated width of the tolerance interval would be reduced by only about $0.06 \mathrm{unit} / \mathrm{ml}$ by adding a fifth determination, we recommend tolerance intervals based on four determinations at 6 -wk intervals.

The tolerance limits are influenced not only by the number of determinations per child, but also by the number of children in each age group. Our tolerance limits are based on 14-15 subjects per group. The tolerance limits will, in theory, decrease with an increase in the number of subjects per group. For example, had we chosen thirty 7 -yr-old boys instead of 15 , the tolerance interval would be $(0.235,0.755)$ assuming that the mean and $\mathrm{SD}$ based on 15 subjects would remain the same if 30 subjects were observed and by using 30 instead of 15 for $n$. Comparison of this interval to that based on 15 subjects $(0.218,0.772)$ shows that only a small reduction would be achieved by increasing the group size from 15 to 30 .

The prevalence of subnormal SmC among short children. Our data show that in children below the third percentile in height, there is a 20 -fold excess of low $\mathrm{SmC}$ levels for chronologic age (45\% versus $2 \%$, Fig. 3 ). About $40 \%$ of the excess of low SmC in the present series is caused by either total or partial GHD. About $40 \%$ of the excess cannot be ascribed to GHD, and the following possibilities can be considered. First, the low SmC could be related to the delayed maturation. As Bala et al. (8) showed and we have confirmed, plasma SmC increases in prepubertal children with chronologic age. The normal mean SmC level for 5-yr olds, for example, is substantially less than for 10 yr olds. The excess of low SmC values in our short, non-GHD 7-10 year olds, therefore, could be related to their retarded bone age (average bone age/chronologic age, 0.66 ).

A second possibility is a failure of nocturnal secretion of hGH as described by Wise et al. (9); this has been ruled out by the nocturnal serum GH data (10). Other causes cannot be excluded: Impaired hepatic production of SmC; nutritional disorders (11); abnormally rapid clearance of $\mathrm{SmC}$; an altered $\mathrm{SmC}$ binding system (12); or a bioinactive GH (3-5) are possible, but are generally outside the scope of the present data. Average weight was appropriate for height (Table 2), tending to rule out severe malnutrition. The possibility of a bioinactive $\mathrm{GH}$ is considered in the accompanying report (10).

The linear growth response. If we take a $5 \mathrm{~cm} / \mathrm{yr}$ or greater increment in growth velocity as a satisfactory response to $\mathrm{GH}$ treatment, then at the $0.26 \mathrm{unit} / \mathrm{kg} / \mathrm{wk}$ dose about $25 \%$ of the non-GHD hyposomatomedinemic short children were responders. At the next higher dose, the proportion of satisfactory responses increased to $60 \%$. Thus our data support the recent series of reports (2-6) that linear growth response to hGH is not a unique feature of GHD children but can be elicited in many non-GHD hyposomatomedinemic short children. At conventional GH treatment doses (up to $0.43 \mathrm{unit} / \mathrm{kg} / \mathrm{wk}$ ), the magnitude of the response by such children was less than $60 \%$ as great as that of their GHD counterparts. At the highest dose of 0.70 unit $/ \mathrm{kg} / \mathrm{wk}$, the response by the non-GHD hyposomatomedinemic short children resembled that of the GHD patients, but only a few in each group (three and four, respectively) were tested at this dose.

Van Vliet et al. (13) have shown that some short stature children with normal SmC respond to hGH with accelerated linear growth. Such children were not included in phase 2 of the present study.

The prevalence of GHD in our series of 97 short children was $20 \%$, while in four cities of England and Scotland the prevalence was less than $2 \%(14,15)$. This difference suggests selectivity in the referral of children to this study by the collaborating pediatricians.

Acknowledgments. William P. Heath and Carol J. Berry provided skillful technical assistance.

\section{REFERENCES}

1. Furlanetto RW, Underwood LE, Van Wyk JJ, D'Ercole AJ 1977 Estimation of somatomedin-C levels in normals and patients with pituitary disease by radioimmunoassay. J Clin Invest 60:648-657

2. Hayek A, Peake GT 1981 Growth and somatomedin-C responses to growth hormone in dwarfed children. J Pediat 99:868-872

3. Kaworski AA, Schneider J, Ben-Galim E, Weldon VV, Daughaday WH 1978 Growth failure with normal serum RIA-GH and low somatomedin activity: Somatomedin restoration and growth acceleration after exogenous GH. J Clin Endocrinol Metab 47:461-464

4. Rudman D, Kutner MH 1981 Blackston RD, Cushman RA, Bain RP, Patterson JH 1981 Children with normal-variant short stature: Treatment with human growth hormone for six months. New Engl J Med 305:123-131

5. Frazer T, Gavin J, Daughaday WH, Hillman RE, Weldon VV 1982 Growth 
hormone-dependent growth failure. J Pediat 101:12-15

6. Blethen SL, Chasalow FI 1983 Use of a two-site immunoradiometric assay for growth hormone $(\mathrm{GH})$ in identifying children with $\mathrm{GH}$-dependent growth failure. J Clin Endocrinol Metab 57:1031-1035

7. Frasier SD 1974 A review of growth hormone stimulation tests in children. Pediatrics 53:020-037

8. Bala RM, Lopatka J, Leung A, McCoy E, McArthur RG 1981 Serum immunoreactive somatomedin levels in normal adults, pregnant women at term, children at various ages, and children with constitutionally delayed growth. J Clin Endocrinol Metab 52:508-512

9. Wise PH, Burnet RB, Geary D, Berriman H 1975 Selective impairment of growth hormone response to physiological stimuli. Arch Dis Child 50:210214

10. Rudman D, Chawla RK, Kutner MH 1985 Heterogeneity of growth hormone in the nocturnal serum of children. Pediatr Res 19:000-000

11. Hintz RL, Suskind R, Amatayakul K, Thanagkul O, Olson R 1978 Plasma somatomedin and growth hormone values in children with protein-calorie malnutrition. J Pediat 92:153-156

12. Morris DH, Schalch DS 1982 Structure of somatomedin-binding protein: alkaline $\mathrm{pH}$-induced dissociation of an acid-stable, 60,000 molecular weight complex into smaller components. Endocrinology 111:801-805

13. Van Vliet G, Styne DM, Kaplan SL, Grumbach MM 1983 Growth hormone treatment for short stature. New Engl J Med 309:1061

14. Lacey KA, Parkin JM 1974 Causes of short stature. A community study of children in Newcastle-upon-Tyne. Lancet 1:42

15. Vimpani GV, Vimpani AF, Lidgard GP, Cameron EHD, Farquhar JW 1977 Prevalence of severe growth hormone deficiency. Br Med J 2:427 